WellBeing International

WBI Studies Repository

1991

\title{
Gender, Sex Role Orientation, and Attitudes toward Animals
}

Harold A. Herzog Jr.

Western Carolina University

Nancy S. Betchart

Western Carolina University

Robert B. Pittman

Western Carolina University

Follow this and additional works at: https://www.wellbeingintlstudiesrepository.org/acwp_sata

Part of the Animal Studies Commons, Other Anthropology Commons, and the Other Feminist, Gender, and Sexuality Studies Commons

\section{Recommended Citation}

Herzog Jr, H. A., Betchart, N. S., \& Pittman, R. B. (1991). Gender, sex role orientation, and attitudes toward animals. Anthrozoös, 4(3), 184-191.

This material is brought to you for free and open access by WellBeing International. It has been accepted for inclusion by an authorized administrator of the WBI Studies Repository. For more information, please contact wbisr-info@wellbeingintl.org.

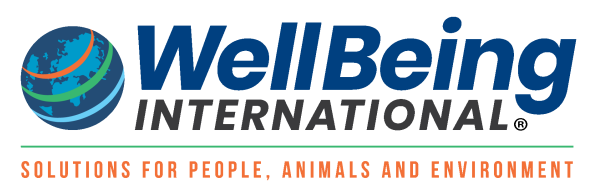




\title{
Gender, Sex Role Orientation, and Attitudes toward Animals
}

\author{
Harold A. Herzog Jr., Nancy S. Betchart \& Robert B. Pittman \\ Western Carolina University
}

\begin{abstract}
To examine the relationship among gender, sex role orientation, and attitudes toward the treatment of animals, 144 male and 222 female college students were administered the Bem Sex Role Inventory, a Likert-scale questionnaire designed to assess attitudes toward animal welfare issues, and a measure of perceived comfort touching animals of a variety of species. There were significant gender differences on all of the animal-related measures with the exception of self-reported comfort touching positively perceived animals. Gender and the expressive (feminine) dimension of sex role orientation accounted for a significant proportion of the variation in attitudes toward animal welfare issues and comfort with other species. Correlations between the masculine and feminine dimensions of sex role orientation were related in opposite directions on all animal attitude measures.
\end{abstract}

\section{SEX ROLE IDENTITY AND ATTITUDES TOWARD ANIMALS}

One of the more intriguing aspects of changing societal views concerning our ethical responsibilities toward other species is the existence of large sex differences in attitudes toward the treatment of animals. Attitude surveys have consistently found that, compared to men, women are less tolerant of abuses of animals and have less utilitarian views concerning other species. For example, Gallup and Beckstead (1988) reported that female undergraduates showed more concern for pain and suffering of laboratory animals than male students, and Tennov (1986) found that more females than males claimed that they would refuse to shock an animal as part of a hypothetical experiment. Using the most extensive data set available on the attitudes of Americans toward animals, Kellert and Berry (1987) found sex differences on almost all dimensions of attitudes and knowledge about animals and concluded that sex differences were so large as to suggest that men and women have different emotional and cognitive orientations toward animals. They reported that women's attitudes toward animals were characterized by humanistic and moralistic orientations, whereas men's were more utilitarian and "dominionistic."

Gender differences in knowledge of and attitudes toward animals appear to develop during or before adolescence, depending on the dimension investigated. Sex differences in knowledge of animals, fears of animals, and species preference have been reported to emerge by the elementary school years (Bowd 1984; Kidd and Kidd 1990; Ollila, Bullen, and Collis 1989). Melson and Fogel (1989) recently reported that boys, but not girls, develop more detailed knowledge of animal young and animal caregiving between preschool and the second grade. Gender differences in moral concern for animals, however, may not be evidenced until later in adolescence (Kellert and Berry 1987).

Males and females also behave differently toward animals. Kindergarten boys and girls exhibit different behaviors toward some species (Nielsen and Delude 1989), male and female horse owners treat their animals differently (Brown 1984), and female children assume more responsibility for pets than do their male counterparts (Kidd and Kidd 1990). Not surprisingly, gender differences are also reflected in the relative involvement of men and women in the animal rights movement. While precise numbers are lacking, there is a substantial female bias in membership of both animal welfare and animal rights organizations (Sperling 1988). A recent survey of vegetarians, most of whom reported that the ethics of consuming animal flesh were a consideration in their dietary preferences, produced a sample composed of $71 \%$ women and $29 \%$ men (Amato and Partridge 1989).

The existence of sex differences in both attitudes and behavior toward animals seems to be a widespread phenomenon. However, little is known about how various aspects of gender and sex role produce the observed differences between males and females. In this study, we used the Bem Sex Role Inventory (BSRI) (Bem 1974, $1977,1981)$ to examine the relationship among gender, sex role, and attitudes toward other species. The BSRI is one of the most commonly used personality inventories in the current psychological literature, and, while not without criticism (e.g., Lenney 1979; Spence and Helmreich 1979, 1980; see also Cook 1985), it has the advantage of being the subject of a considerable body of research, including a number of validity studies (e.g., Taylor 1984; Ramanaiah and Martin 1984; Wilson and Cook 1985). 
The BSRI conceptualizes sex roles along a two-dimensional matrix rather than the traditional male-female dimension. One dimension of the BSRI is an affective-expressive dimension with men stereotypically lying on the non-expressive side of the continuum and females falling on the expressive side. The second dimension reflects instrumentality, with men having higher scores. Therefore, an individual could score high on both instrumental (masculine) and expressive (feminine) characteristics. Individuals who score high on both dimensions are referred to as androgynous and are presumed to have sex role orientations that allow for more flexibility with regard to sex-stereotyped behaviors (Bem 1975). Individuals who score low on both dimensions are referred to as undifferentiated.

As mentioned, sex role orientation has been found to be related to how individuals respond to animals; for example, feminine and androgynous males were reported to be more likely to play with a kitten than males with traditional sex role orientation (Bem 1975). But the relation between sex role orientation and attitudes toward the use of other species has largely been neglected. We hypothesized that both the instrumental (masculine) and the expressive (feminine) dimensions of the BSRI would be related to attitudes toward the use of animals. Specifically, we predicted that both gender and sex role orientation would be related to (a) general attitudes toward the use of animals and animal suffering, (b) the tendency to report a willingness to become actively involved in helping animals in distress, and (c) the degree of comfort touching animals of different species. In addition, we hypothesized that there would be a positive relationship between concern for the treatment of animals and the degree of comfort subjects felt with them.

To test these hypotheses, we developed two scales to be used in conjunction with the BSRI. The first was designed to measure general attitudes toward concern for and use of other species and contained two subscales. One was designed to assess the tendency to take action to further the welfare of mistreated animals, and the other concerned the ethics of their treatment. The second scale measured how comfortable the subjects felt around other species as reflected by their self-reported comfort touching them.

\section{METHODS}

\section{Subjects}

The subjects were 144 male and 222 female undergraduate students recruited from introductory psychology and biology classes at three colleges in North Carolina: a midsized regional state university and two small, private liberal arts colleges. A few students did not complete all of the survey items, and thus group sizes vary slightly for some of the analyses. The subjects ranged in age from 17 to 48 , with a mean age of 21 (SD= 4.9 years). The majority of the subjects (335) were white, with 12 blacks and 18 "others" (Hispanics and Native and Asian Americans). Forty-two percent characterized the area in which they were raised as rural, $37 \%$ as suburban, and $15 \%$ as urban. About $90 \%$ (332) were from the southern United States.

\section{Instruments}

In addition to questions designed to elicit demographic information such as age, race, state in which subjects were raised, and political orientation, the following instruments were used to collect data.

\section{Bem Sex Role Inventory.}

The BSRI is a list of 20 characteristics typically attributed to women (e.g., love children, sensitive to needs of others, gentle), 20 characteristics usually attributed to men (e.g., competitive, defend my own beliefs, have leadership abilities), and 20 neutral characteristics (e.g., conscientious, moody, truthful). Subjects rate the degree to which each trait describes their personalities on a seven-point scale (1=never or almost never true, 7=always or almost always true). Two methods have been used to analyze BSRI data. In the original version of the BSRI, each subject was assigned a sex role orientation category (masculine, feminine, or androgynous) based on median splits. However, Bem (1977) later advocated the use of multiple regression techniques for the analysis of BSRI data, and we applied this approach in the present study.

Note that it is somewhat misleading to refer to males describing themselves as gentle and sensitive as "feminine" and women describing themselves as leaders as "masculine." However, according to convention, we will use these terms in the following contexts: The term masculine refers to a constellation of traits associated with instrumentality, achievement, dominance, and competitiveness. Feminine, on the other hand, refers to traits associated with expressiveness, sensitivity, and nurturance. The terms do not refer to sexual preference or transgender behavior patterns (i.e., effeminate males or masculine females). 
The Animal Attitude Scale designed for this study consisted of 29 Likertscale statements assessing attitudes toward the use of animals. Each of the items was scored on a five-point scale (strongly agree, agree, undecided, disagree, strongly disagree). The scale had acceptable psychometric properties, with a Cronbach's alpha of .88, indicating high internal consistency (Poresky 1989). Nine of the items were written to assess the tendency to become actively involved in animal welfare (e.g., "I would be unlikely to stop my car to help an injured dog" or "If I had the opportunity, I would sign a petition in support of stricter animal welfare laws"). These are referred to as the Take Action Subscale. The remaining 20 items measured attitudes toward the treatment and use of animals, including their use as food, clothing (furs), recreational resources (hunting, zoos), and research. Typical items included: 'There is something morally wrong about hunting wild animals just for sport," "I do not think there is anything wrong with using animals in medical research," and "Too much fuss is made over the welfare of animals these days when there are many human problems that need to be solved." These 20 items are collectively referred to as the Ethics Subscale. High scores on these attitude measures reflected greater concern for the welfare of other species.

\section{Comfort Scale.}

A second instrument was developed to assess the extent to which people felt comfortable with animals by having them indicate how they would feel about touching them. It consisted of a list of 15 species (butterfly, hamster, canary, earthworm, nonpoisonous spider, kitten, toad, duck, horse, harmless snake, mouse, turtle, large dog, chicken, bat) that subjects rated along with a five-point scale on which 1 indicated "would be very comfortable touching" and 5 indicated "would be very uncomfortable touching." Each individual's total Comfort score was determined by summing the circled number for each of the 15 species. In the analysis, the item values were reversed so that a high score indicated a higher degree of comfort touching the animal. Thus, the minimum score of 15 would be given to a person who said she or he would feel uncomfortable touching all of the species, whereas the maximum score of 75 would be characteristic of a person who said she or he would feel very comfortable touching any of the species.

Factor analysis of the scale indicated that there were two distinct factors, one corresponding to animals that are generally perceived positively (butterfly, hamster, canary, kitten, duck, horse, dog) and the other consisting of animals typically viewed more negatively (worm, spider, toad, snake, mouse, bat). Two animals failed to load clearly on either factor-chicken and turtle. We subsequently divided the Comfort Scale into two subscales. The first consisted only of the positive animals, and the second consisted of the negative animals. Responses to chickens and turtles were included on the overall Comfort Scale but not on the positive and negative animal subscales.

\section{Data Analysis}

Data were analyzed using standard parametric procedures (t-tests, Pearson correlation coefficients, multiple regression) with two-tailed statistical tests. Since one of our primary interests was male/female differences, it was necessary to consider whether the interaction between gender and sex role orientation was an important contributor to predicting the measures of attitudes toward animals. The multiple regression indicated that this interaction was not significant; therefore, it was not included in the analysis.

\section{RESULTS}

There were highly significant gender differences for all of the attitude measures except closeness to positively perceived animals (Table 1). As hypothesized, males showed less concern for animal welfare issues than did females both in terms of the self-reported tendency to take action to help members of other species and in sensitivity to their use by humans.

Table 2 shows how various species were evaluated by males and females on the Comfort Scale. Generally, women were as likely as men to report that they were comfortable touching "nice" animals such as kittens and butterflies but were less comfortable than men with animals having more negative reputations (e.g., spiders, snakes, toads). The only closeness scores that were significantly higher for female than male subjects were for horses and dogs.

The correlations between the attitude measures and the closeness to animal measures are shown in Table 3. Note that correlations between the total Animal Attitude Scale and the two subscales (Ethics and Take Action) are high by definition. This is also true for the high correlations between the two subscales measuring how various species are perceived (positively and negatively perceived animals) and the total Comfort Scale. The data in this table indicate that there was a strong relationship between the self-reported tendency to take action and ethical sensitivities concerning the use of animals $(R=.68)$. There was a moderate positive correlation between the comfort scores for the positively and negatively perceived animals $(R=.40)$. However, the other correlations were either not significant or statistically significant but low. In contrast to our expectations, the correlation between the total Animal Attitude Scale 
and the Comfort Scale was not significant $(R=.08)$, indicating that perceived comfort around animals is not necessarily related to attitudes about how we should treat them.

The overall relationship among gender, sex role orientation (BSRI Feminine and Masculine scale scores), and attitudes toward animals was investigated using a two-step analytical strategy. In the first step, a canonical correlation was used to determine the degree of relationship between gender-related variables and attitude variables. The overall correlation between the gender-related variables (gender, BSRI Masculine score, BSRI Feminine score) and the attitude scores was .47. Examination of the standardized canonical weights indicated that the variables that contributed most to understanding the relationship were gender, the Feminine Scale scores, the Take Action Scale score, and the Negative Animals score.

Table 1. Means (and Standard Deviations) of Males and Females on Scales Related to Sex Role Orientation and Attitudes Toward Animals

\begin{tabular}{|lcccccc|}
\hline & \multicolumn{2}{c}{ Males } & & \multicolumn{2}{c|}{ Females } & \\
\cline { 2 - 3 } Scale & Mean & SD & & Mean & SD & T-test \\
\hline BSRI Feminine & 4.6 & 0.5 & & 5.2 & 0.5 & $9.27^{\star \star}$ \\
BSRI Masculine & 5.2 & 0.6 & & 4.8 & 0.7 & $5.16^{\star \star}$ \\
Take Action & 30.5 & 5.2 & & 33.2 & 5.1 & $4.77^{\star \star}$ \\
Ethics & 63.7 & 11.6 & & 68.3 & 10.6 & $3.86^{\star \star}$ \\
Total Attitude $^{\mathrm{a}}$ & 94.3 & 15.5 & & 101.3 & 14.5 & $4.35^{\star \star}$ \\
Negative animals & 20.5 & 6.8 & & 16.0 & 7.0 & $5.98^{\star \star}$ \\
Positive animals $_{\text {Total Comfort }}^{\mathrm{b}}$ & 31.5 & 5.7 & & 31.9 & 4.5 & 0.68 \\
\hline
\end{tabular}

${ }^{a}$ Refers to combined Take Action and Ethics subscales.

${ }^{b}$ Refers to all of the species included in the Comfort Scale

${ }^{* *} p<.01$

This analysis was followed by a series of multiple regression analyses in which gender and the BSRI Masculine and Feminine scores were used as predictor variables with the following dependent variables: the Take Action Subscale score, the Ethics Subscale score, the total Animal Attitude score, and the scores for the negatively and positively perceived animals as well as those for the total Comfort Scale.

Results from these analyses and the accompanying correlations are presented in Tables 4 and 5 . Together, gender and BSRI Feminine and Masculine scores predicted relatively small but statistically significant portions of variation on the following measures: the Take Action Subscale ( $9 \%$ of the variance), the Ethics Subscale ( $7 \%$ of the variance), the total Animal Attitude Scale (8\% of the variance), and closeness to negatively perceived animals (10\% of the variance). The intercorrelations in Table 4 and the regression results in Table 5 indicate that gender and the BSRI Feminine Scale were the best predictors for most of the attitude scores. Greater concern for animal welfare was associated with being female and having higher BSRI Feminine Scale scores. The importance of the BSRI Feminine Scale in the prediction of attitudes held with the effect of gender partial led out for both males and females. Only for the Ethics Subscale was the BSRI Masculine Scale a significant predictor variable. It is interesting to note that, in all cases, the BSRI Masculine and Feminine scales were related to the dependent variables in opposite directions. Comfort with positively perceived animals was not significantly predicted by either gender or sex role orientation.

\section{DISCUSSION}

In this study, we found significant sex differences in attitudes toward animals and their use. Regression analysis indicated that gender and feminine sex role orientation predict a fairly small but statistically significant portion of individual differences in several such attitudes. Male and female subjects differed on all of the attitude measures except perceived comfort touching positive animals. Feminine sex role orientation as measured by the BSRI was positively correlated with concern for the well-being of other species and inversely correlated with comfort touching them (particularly negatively perceived species). With the exception of the Ethics Subscale, the degree of masculine sex role orientation did not predict attitudes toward other species. However, in all cases, feminine and masculine sex role orientation measures were related to animal attitude scales in opposite directions. 
Table 2. Mean Comfort Scale Scores for Male and Female Subjects

\begin{tabular}{|c|c|c|c|c|}
\hline \multirow[b]{2}{*}{ Species } & \multicolumn{2}{|c|}{$\begin{array}{c}\text { Males } \\
(\mathrm{N}=143)\end{array}$} & \multicolumn{2}{|c|}{$\begin{array}{c}\text { Females } \\
(\mathrm{N}=221)\end{array}$} \\
\hline & Mean & SD & Mean & SD \\
\hline Kitten & 4.81 & 0.68 & 4.86 & 0.63 \\
\hline Horse ${ }^{\star \star}$ & 4.55 & 0.98 & 4.79 & 0.66 \\
\hline Dog* & 4.31 & 1.21 & 4.58 & 0.87 \\
\hline Duck & 4.50 & 0.99 & 4.50 & 0.85 \\
\hline Butterfly & 4.46 & 1.01 & 4.36 & 1.04 \\
\hline Hamster & 4.46 & 1.01 & 4.37 & 1.04 \\
\hline Canary & 4.41 & 1.01 & 4.41 & 0.92 \\
\hline Turtle & 4.48 & 0.97 & 4.34 & 1.01 \\
\hline Chicken & 4.04 & 1.21 & 3.81 & 1.24 \\
\hline 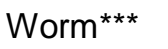 & 4.13 & 1.18 & 3.07 & 1.50 \\
\hline Toad ${ }^{\star \star \star}$ & 3.92 & 1.26 & 3.31 & 1.43 \\
\hline Mouse ${ }^{\star \star \star}$ & 3.68 & 1.44 & 3.10 & 1.59 \\
\hline Snake & 3.32 & 1.63 & 2.62 & 1.64 \\
\hline Spider ${ }^{\star * *}$ & 3.04 & 1.51 & 2.09 & 1.39 \\
\hline Bat $^{\star \star \star}$ & 2.38 & 1.49 & 1.84 & 1.23 \\
\hline
\end{tabular}

Note: The species were rated from 5 (*I would feel very comfortable touching the animal to 1 (*I would feel very uncomfortable touching the animal").

${ }^{*} p<.05$

$* * p<.01$

$* * * p<.001$

Table 3. Correlations Between Attitude and Closeness to Animals Scales

\begin{tabular}{|lccccc|}
\hline Scale & $\begin{array}{c}\text { Take } \\
\text { Action }\end{array}$ & Ethics & $\begin{array}{c}\text { Total } \\
\text { Attitude }\end{array}$ & $\begin{array}{c}\text { Negative } \\
\text { Animal }\end{array}$ & $\begin{array}{c}\text { Positive } \\
\text { Animal }\end{array}$ \\
\hline Ethics & $.68^{\star \star}$ & & & & \\
Total Attitude & $.85^{\star \star^{\mathrm{a}}}$ & $.97^{\star \star^{\mathrm{a}}}$ & & & \\
Negative Animal & $.13^{\star}$ & -.04 & .02 & & \\
Positive Animal & $.20^{\star \star}$ & .07 & $.12^{\star}$ & $.40^{\star \star}$ & \\
Total Comfort & $.20^{\star \star}$ & .02 & .08 & $.88^{\star *^{\mathrm{a}}}$ & $.77^{\star *^{\mathrm{a}}}$ \\
\hline
\end{tabular}

Note: See text for explanation of the scales.

${ }^{a}$ Indicates correlations between scale and subscale

$* p<.05$

${ }^{* *} p<.01$

Scores on the BSRI Feminine Scale correspond to nurturance/warmth and expressive components of personality whereas the BSRI Masculine Scale appears to represent the dominance/poise and instrumental aspects (Baldwin et al. 1986). Our results suggest that the nurturance-expressive dimension of personality is more highly related to concern for animal welfare than is the dominance-instrumental dimension. The relation is also in the opposite direction; higher feminity is related to increased concern about other species, whereas increased masculinity is related, though to a lesser degree, with lower sensitivity to the ethical treatment of other creatures. These findings are particularly interesting in light of the explosive growth in the membership of animal rights groups in recent years. Women are disproportionately represented in these organizations (see, e.g., Sperling 1988; Kaplan and Herzog unpublished data). In a series of interviews with rank-and-file animal rights activists, Herzog (1990) found that the themes of nurturance and concern were especially evident in the thinking of the female interviewees. 
Table 4. Correlations Among Gender, Sex Role Orientation, and Attitude Scales

\begin{tabular}{|lccc|}
\hline Scale & BSRI Feminine & BSRI Masculine & Gender* \\
\hline Take Action & $.25^{\star \star}$ & -.02 & $-.24^{\star \star}$ \\
Ethics & $.19^{\star *}$ & $-.16^{\star *}$ & $-.19^{\star \star}$ \\
Total Attitude & $.23^{\star *}$ & $-.13^{\star}$ & $-.22^{\star \star}$ \\
Negative Animal & $-.22^{\star *}$ & $.12^{\star}$ & $.31^{\star *}$ \\
Positive Animal & -.03 & -.01 & -.04 \\
Total Comfort & $-.15^{\star *}$ & .09 & $.19^{\star *}$ \\
\hline
\end{tabular}

${ }^{a}$ Gender was coded 0 for female, 1 for male

$* p<.05$

$* * p<.01$

Table 5. Multiple Regressions and Standardized Regression Weights Describing How Gender and BSRI Feminine and Masculine Scales Contribute to the Prediction of the Dependent Variable

\begin{tabular}{|c|c|c|c|c|}
\hline \multirow[b]{2}{*}{ Scale } & \multirow[b]{2}{*}{ Multiple Regression } & \multicolumn{3}{|c|}{ Standard regression weights } \\
\hline & & BSRI Feminine & BSRI Masculine & Gender \\
\hline Take Action & .295 & $.18^{\star \star}$ & .02 & $-.17^{\star \star}$ \\
\hline Ethics & .259 & $.14^{*}$ & $-.13^{*}$ & -.10 \\
\hline Total Attitude & .277 & $.17^{\star \star}$ & -.09 & $-.13^{*}$ \\
\hline Negative Animal & .323 & $-.12^{\star}$ & .07 & $.22^{\star *}$ \\
\hline Positive Animal & .059 & -.06 & .00 & -.05 \\
\hline Total Comfort & .206 & -.10 & .05 & $.12^{*}$ \\
\hline
\end{tabular}

$* p<.05$

$* * p<.01$

There is no shortage of possible explanations as to why women generally show greater sensitivity to the treatment of animals. Sociocultural theorists would no doubt argue that women are socialized from birth for nurturant and caring roles while men are trained to be less emotional and more utilitarian and this manifests itself in their respective feelings about the use of animals. For example, Hills (1989) recently reported that females were more "person oriented" and favored cute, cuddly animals, whereas males tended to be more "thing oriented" and preferred less attractive species. Those with a penchant for biological explanations (see Burghardt and Herzog 1989) would argue that the roots of sex differences might ultimately reside in differing evolutionary pressures. (Females may be attracted to some animals by a misfiring of maternal urges, and the attraction of men to blood sports is perhaps a result of selection favoring males with hunting skills.) Cognitive developmental psychologists, on the other hand, might interpret gender difference in terms of differing moral orientations (care versus justice) (e.g., Gilligan and Attanucci 1988; Kellert and Berry 1987; Lyons 1983; but see Walker 1984, 1986).

Like all studies, this study has certain limitations and also suggests areas in which additional research is warranted. Our sample consisted largely of southern, white college students, and, while we anticipate that the results will be generally applicable, more research needs to be done with other populations. In addition, there is controversy over the adequacy of measures such as the BSRI that attempt to reduce complex concepts like masculinity or femininity to unidimensional scales (Myers and Gonda 1982).

Finally, roughly $90 \%$ of the individual variation in the various attitude measures was not accounted for by gender or sex role orientation. This finding suggests that researchers seeking to explicate factors predicting sensitivity, cruelty, and kindness toward other creatures will have enough work to remain busy for the foreseeable future. 


\section{REFERENCES}

Amato, P.R., and S.A.Partridge. 1989. The new vegetarians: Promoting health and protecting life. New York: Plenum.

Baldwin, A.C., L.C.Stevens, J.W.Critelli, and S. Russell. 1986. Androgyny and sex role measurement: A personal construct approach. Journal of Personality and Social Psychology 51:1081-88.

Bem, S.L. 1981. Bem Sex Role Inventory professional manual. Palo Alto, Calif.: Consulting Psychologists Press.

- 1977. On the utility of alternative procedures for assessing psychological androgyny. Journal of Counseling and Clinical Psychology 45: 196-205.

—. 1975. Sex role adaptability: One consequence of psychological androgyny. Journal of Personality and Social Psychology 31:634-43.

- 1974. The measurement of psychological androgyny. Journal of Consulting and Clinical Psychology 47:155-62.

Bowd, A.D. 1984. Fears and understanding of animals in middle childhood. The Journal of Genetic Psychology 145:143-44.

Brown, D.S. 1984. Human gender, age, and personality effects on relationships with dogs and horses. Ph.D. diss., Duke University, Durham, N.C.

Burghardt, G.M., and H.A.Herzog, Jr. 1989. Animals, evolution, and ethics. In Perceptions of animals in American culture, ed. R.J.Hoage, pp. 129-51. Washington, D.C.: Smithsonian Institution Press.

Cook, E.P. 1985. Psychological androgyny. New York: Pergamon.

Gallup, G.G., Jr., and J.W.Beckstead. 1988. Attitudes toward animal research. American Psychologist 43:474-76.

Gilligan, C., and J.Attanucci. 1988. Two moral orientations: Gender differences and similarities. Merrill-Palmer Quarterly 34:223-37.

Herzog, H. 1990. "The movement in my life": The psychology of animal rights activism. Paper presented at the meeting of the Animal Behavior Society, Binghamton, New York.

Hills, A.M. 1989. The relationship between thing-person orientation and the perception of animals. Anthrozoös 3:100110.

Kellert, S.R., and J.K.Berry. 1987. Attitudes, knowledge, and behaviors toward wildlife as affected by gender. Wildlife Society Bulletin 15:363-71.

Kidd, A., and R.M.Kidd. 1990. Factors in children's attitudes toward pets. Psychological Reports 66: 775-86.

Lenney, E. 1979. Androgyny: Some audacious assertions toward its coming of age. Sex Roles 5:703-19.

Lyons, N.P. 1983. Two perspectives: On self, relationships, and morality. Harvard Educational Review 53:125-45.

Melson, G.F., and A.Fogel. 1989. Children's ideas about animal young and their care: A reassessment of gender differences in the development of nurturance. Anthrozoös 2:265-73.

Myers, A.M., and G.Gonda. 1982. Utility of the masculinity-femininity construct: Comparison of traditional and androgyny approaches. Journal of Personality and Social Psychology 43:514-23.

Nielson, J.A., and L.A.Delude. 1989. Behavior of young children in the presence of different kinds of animals. Anthrozoös 3:119-29.

Ollila, L., C.Bullen, and B.Collis. 1989. Gender-related preference for the choice of particular animals as writing topics in grade 1. Journal of Research and Development in Education 22:37-41.

Poresky, R.H. 1989. Analyzing human-animals relationship measures. Anthrozoös 2:236-44.

Ramanaiah, N.J., and H.J.Martin. 1984. Convergent and divergent validity of selected masculinity and femininity scales. Sex Roles 10:493-504. Spence, J.T., and R.L.Helmreich. 1980. Masculine instrumentality and feminine expressiveness: Their relationships with sex role attitudes and behaviors. Psychology of Women Quarterly 5:147-63.

1979. On assessing "androgyny." Sex Roles 5:721-37.

Sperling S. 1988. Animal liberators: Research and morality. Berkeley: University of California Press.

Taylor, D. 1984. Concurrent validity of the Bem Sex Role Inventory: A person-environment approach. Sex Roles 10:713-23.

Tennov, D. 1986. Pain-infliction in animal research. In Animals in education, ed. H.McGiffin and N.Brownley, pp. 3540. Washington, D.C.: Institute for the Study of Animal Problems.

Walker, L.J. 1986. Experiential and cognitive sources of moral development in adulthood. Human Development 29:113-24.

- 1984. Sex differences in the development of moral reasoning: A critical review. Child Development 55:677-91.

Wilson, F.R., and E.P.Cook. 1985. Concurrent validity of four androgyny instruments. Sex Roles 11: 813-37. 